\title{
Influence of along-valley terrain heterogeneity on exchange processes over idealized valleys
}

\author{
J. S. Wagner, A. Gohm, and M. W. Rotach \\ Institute of Meteorology and Geophysics, University of Innsbruck, Austria \\ Correspondence to: J. S. Wagner (johannes.wagner@uibk.ac.at)
}

Received: 9 October 2014 - Published in Atmos. Chem. Phys. Discuss.: 7 January 2015

Revised: 8 May 2015 - Accepted: 15 May 2015 - Published: 16 June 2015

\begin{abstract}
Idealized numerical simulations of thermally driven flows over various valley-plain topographies are performed under daytime conditions. Valley floor inclination and narrowing valley cross sections are systematically varied to study the influence of along-valley terrain heterogeneity on the developing boundary layer structure, as well as horizontal and vertical transport processes. Valley topographies with inclined valley floors of $0.86^{\circ}$ increase upvalley winds by a factor of about 1.9 due to smaller valley volumes (volume effect) and by a factor of about 1.6 due to additional upslope buoyancy forces. Narrowing the valley cross section by $20 \mathrm{~km}$ per $100 \mathrm{~km}$ along-valley distance increases upvalley winds by a factor of about 2.6. Vertical mass fluxes out of the valley are strongly increased by a factor between 1.8 and 2.8 by narrowing the valley cross sections and by a factor of 1.2 by inclining the valley floor. Trajectory analysis shows intensified horizontal transport of parcels from the foreland into the valley within the boundary layer in cases with inclined floors and narrowing cross sections due to increased upvalley winds.
\end{abstract}

\section{Introduction}

Thermally driven flows are well known phenomena under fair weather conditions over complex terrain. They are driven by differential heating of adjacent air masses and are characterized by diurnally changing flow patterns (Whiteman, 2000). Several authors have investigated mechanisms which induce thermally driven flows and have developed analytical models and basic concepts to describe the formation of upslope and upvalley winds. Among these are e.g. the slope wind models of Prandtl (1952) and Vergeiner and Dreiseitl (1987) or the valley volume effect (e.g. Wagner, 1938; Schmidli, 2013). The existence of thermally driven flows has a significant impact on the developing boundary layer structure over complex terrain, which differs considerably from boundary layers over flat plains (e.g. Egger, 1990; Rotach and Zardi, 2007; Wagner et al., 2014a).

The importance of thermally driven flows for the planetary boundary layer (PBL) over complex terrain and their contribution to horizontal and vertical transport processes has been examined in several observational and modelling studies in the past (e.g. Henne et al., 2004; Weissmann et al., 2005; Weigel et al., 2007; Wagner et al., 2014a, b). Measurements and numerical modelling showed that vertical moisture transport over a valley can be 3-4 times larger than over flat and homogeneous terrain during a summer day with fair weather conditions (Weigel et al., 2007). Recent idealized simulations confirmed these values (Wagner et al., 2014a) and demonstrated that the vertical transport can be up to 8 times larger over a valley compared to a plain depending on the reference surface through which vertical transport is assessed and which is associated with different definitions of the boundary layer height.

This characteristic of thermally driven flows to transport properties like pollutants, moisture or trace gases (e.g. $\mathrm{CO}_{2}$ ) over large horizontal and vertical distances is of great importance for regional climate and weather prediction (Rotach et al., 2014). The correct simulation of these mesoscale flows requires, however, a proper representation of topography and land-use type in numerical models and therefore appropriate horizontal grid resolutions. It is supposed that operational mesoscale models will be able to simulate thermally driven flows over complex terrain properly in the near future, as they already use horizontal grid sizes of about $1 \mathrm{~km}$ 
today. Deep and narrow valleys will, however, not appropriately be resolved by global numerical weather prediction (NWP) and climate models in the next decades and improved parametrization schemes for boundary layer processes are needed. These schemes have to be adapted to complex terrain and should include effects of thermally driven flows, which cannot be resolved (Rotach and Zardi, 2007).

First steps to improve existing boundary layer parametrizations could consist in the systematic investigation of the impact of valley geometry, thermal forcing or land-use type on thermally driven flows and related exchange processes (e.g. Wagner et al., 2014a). In the past, idealized modelling studies have been performed to investigate the impact of valley width (e.g. Serafin and Zardi, 2010; Catalano and Cenedese, 2010), valley depth (e.g. Colette et al., 2003) and slope inclination (e.g. Schumann, 1990). However, apart from the study of $\mathrm{Li}$ and Atkinson (1999), in which valleys with different floor inclinations and narrowing valley cross sections were used, in most modelling studies valleys with homogeneous along-valley topography were investigated (e.g. Rampanelli et al., 2004; Schmidli and Rotunno, 2010; Schmidli et al., 2011; Schmidli, 2013; Wagner et al., 2014a, b). When considering real valleys such as the Inn Valley, the Isar Valley or the Oetz Valley in the European Alps, it is evident that the valley geometry typically changes in the along-valley direction. To consider more realistic valley geometries, this study aims at systematically investigating the influence of along-valley terrain inhomogeneity on thermally driven flows and transport processes. This is achieved by both tilting the valley floor and narrowing the valley cross section in the along-valley direction.

The paper is organized as follows: the model setup is described in Sect. 2, the simulation results are presented in Sect. 3 and a conclusion is given in Sect. 4.

\section{Model setup}

In this study the Advanced Research version of the Weather Research and Forecasting model (WRF-ARW), version 3.4 (Skamarock et al., 2008) is used for idealized numerical simulations. The WRF model has been successfully applied for idealized simulations of thermally driven flows in the kilometre scale (Rampanelli et al., 2004; Schmidli et al., 2011; Wagner et al., 2014b) and for large-eddy simulation (LES) studies (Catalano and Moeng, 2010; Catalano and Cenedese, 2010; Wagner et al., 2014a, b) in the past.

The WRF model is a non-hydrostatic, fully compressible numerical model, which uses a horizontally staggered Arakawa-C grid with a terrain-following dry-hydrostatic pressure vertical coordinate (Skamarock et al., 2008). A third-order Runge-Kutta time integration scheme, fifthorder horizontal and third-order vertical advection scheme is adopted in this study. The model is used in LES mode which means that subgrid-scale turbulence is parametrized by a $1.5-$ order 3-dimensional turbulent kinetic energy (TKE) closure (Deardorff, 1980). At the surface a Monin-Obukhov similarity scheme (Monin and Obukhov, 1954) using four stability regimes of Zhang and Anthes (1982) is applied. The decomposition of the turbulent flow into resolved and mean components is done according to the method described in Wagner et al. (2014b). In order to reduce the amount of data storage needed for computations a statistics module is implemented in the WRF model, which allows for an online averaging and flux computation while the model is integrating.

The used valley topography is similar to the model terrain applied in Schmidli et al. (2011). The modelling domain of the reference setup (REF, see Table 1) has an extent of $200 \mathrm{~km}$ in the along-valley and $40 \mathrm{~km}$ in the crossvalley direction. The topography consists of a $1.5 \mathrm{~km}$ deep and $100 \mathrm{~km}$ long and straight valley and a $100 \mathrm{~km}$ long and flat foreland (see Fig. 1a). In order to vary the model topography in along-valley direction (i.e. narrowing valley, inclined valley floor), the terrain computation of Schmidli et al. (2011) is extended following Riday (2010). The along-valley ( $y$-direction) mountain height $h_{y}$ is defined as

$h_{y}(y)= \begin{cases}1, & 0 \leq y \leq L_{y} \\ 0.5+0.5 \cos \left(\pi \frac{y}{S_{y}}\right), & -S_{y}<y<0 \\ 0, & y \leq-S_{y},\end{cases}$

with valley length $L_{y}=100 \mathrm{~km}$ and along-valley sidewall width $S_{y}=9 \mathrm{~km}$. The valley floor height $f_{\text {ly }}$ is computed as

$f_{\mathrm{ly}}(y)= \begin{cases}F_{\operatorname{lmax}}, & F_{\mathrm{e}} \leq y \\ \frac{F_{\max }}{F_{\mathrm{e}}-F_{\mathrm{s}}}\left(y-F_{\mathrm{s}}\right), & F_{\mathrm{s}} \leq y<F_{\mathrm{e}} \\ 0, & y<F_{\mathrm{s}},\end{cases}$

with maximum floor height $F_{1 \max }$ and start and end positions of the inclined valley floor $F_{\mathrm{s}}=0 \mathrm{~km}$ and $F_{\mathrm{e}}=100 \mathrm{~km}$, respectively. Between $F_{\mathrm{s}}$ and $F_{\mathrm{e}}$ the valley floor is linearly increased from zero to the height $F_{\operatorname{lmax}}$. The half-width $w_{y}$ of the valley floor is calculated according to

$w_{y}(y)= \begin{cases}W_{\mathrm{e}}, & F_{\mathrm{e}} \leq y \\ \frac{W_{\mathrm{s}}-W_{\mathrm{e}}}{F_{\mathrm{s}}-F_{\mathrm{e}}}\left(y-F_{\mathrm{s}}\right)+W_{\mathrm{s}}, & F_{\mathrm{s}} \leq y<F_{\mathrm{e}} \\ W_{\mathrm{s}}, & y<F_{\mathrm{s}},\end{cases}$

with the start and end half-widths $W_{\mathrm{s}}$ and $W_{\mathrm{e}}$ at the positions $F_{\mathrm{S}}$ and $F_{\mathrm{e}}$, respectively. As for the valley floor height (Eq. 2), the half-width is varied linearly between $F_{\mathrm{s}}$ and $F_{\mathrm{e}}$. To generate a sequence of parallel valleys, the flat mountain top halfwidth $p_{y}$ is adapted to the corresponding valley width $w_{y}$ by

$p_{y}(y)= \begin{cases}\max \left(w_{y}\right)-w_{y}+P_{x}, & F_{\mathrm{s}} \leq y \leq F_{\mathrm{e}} \\ P_{x}, & y<F_{\mathrm{s}},\left(W_{\mathrm{e}} \leq W_{\mathrm{s}}\right) \\ P_{x}, & y>F_{\mathrm{e}},\left(W_{\mathrm{e}}>W_{\mathrm{s}}\right),\end{cases}$

with a predefined half-width $P_{x}=0.5 \mathrm{~km}$. The 2dimensional valley topography field $h(x, y)$ is then 
Table 1. Set-up of model topographies. REF corresponds to the reference run. Terrain parameters: $W_{\mathrm{s}}$ and $W_{\mathrm{e}}$ for valley width at the valley start and end points, respectively, $F_{\text {lmax }}$ for the floor height at the valley end, $F_{\text {angle }}=\arctan \left(F_{\text {lmax }} / 100\right)$ for the valley floor inclination angle and $V_{\text {ratio }}$ for the ratio of the valley volume $V$ to the valley volume of the reference run $V_{\mathrm{REF}}$.

\begin{tabular}{lrrrrr}
\hline Case & $\begin{array}{r}W_{\mathrm{s}} \\
{[\mathrm{km}]}\end{array}$ & $\begin{array}{r}W_{\mathrm{e}} \\
{[\mathrm{km}]}\end{array}$ & $\begin{array}{r}F_{\text {lmax }} \\
{[\mathrm{km}]}\end{array}$ & $\begin{array}{r}F_{\text {angle }} \\
{[\mathrm{deg}]}\end{array}$ & $\begin{array}{r}V_{\text {ratio }} \\
{\left[V / V_{\mathrm{REF}}\right]}\end{array}$ \\
\hline PLAIN & - & - & - & - & 2.00 \\
REF & $\mathbf{2 0}$ & $\mathbf{2 0}$ & $\mathbf{0}$ & $\mathbf{0}$ & $\mathbf{1 . 0 0}$ \\
I0_375 & 20 & 20 & 0.375 & 0.21 & 0.87 \\
I0_75 & 20 & 20 & 0.75 & 0.43 & 0.75 \\
I1_125 & 20 & 20 & 1.125 & 0.64 & 0.62 \\
I1_5 & 20 & 20 & 1.5 & 0.86 & 0.50 \\
W30 & 30 & 30 & 0 & 0 & 2.00 \\
W30N & 30 & 20 & 0 & 0 & 1.50 \\
W30NI & 30 & 20 & 1.5 & 0.86 & 0.83 \\
W40 & 40 & 40 & 0 & 0 & 3.00 \\
W40N & 40 & 20 & 0 & 0 & 2.00 \\
W40NI & 40 & 20 & 1.5 & 0.86 & 1.16 \\
SL & - & - & 1.5 & 0.86 & 1.00 \\
\hline
\end{tabular}

computed as a combination of $h_{y}, f_{\mathrm{ly}}, w_{y}$ and $p_{y}$ :

$$
h(x, y)= \begin{cases}f_{\mathrm{ly}}, & |x| \leq w_{y} \\ \left(h_{\mathrm{p}} h_{y}-f_{\mathrm{ly}}\right)(0.5- & \\ \left.0.5 \cos \left(\pi \frac{|x|-w_{y}}{S_{x}}\right)\right)+f_{\mathrm{ly}}, & w_{y}<|x| \leq w_{y}+S_{x} \\ h_{\mathrm{p}} h_{y}, & w_{y}+S_{x}<|x| \leq v_{y} \\ h_{\mathrm{p}} h_{y}(0.5+ & \\ \left.0.5 \cos \left(\pi \frac{|x|-v_{y}}{S_{y}}\right)\right) & v_{y}<|x| \leq v_{y}+S_{x} \\ 0, & |x|>v_{y}+S_{x},\end{cases}
$$

with the valley depth $h_{\mathrm{p}}=1.5 \mathrm{~km}$, the cross-valley sidewall width $S_{x}=9 \mathrm{~km}$ and $v_{y}=w_{y}+S_{x}+2 P_{x}$.

The model grid has a horizontal mesh size of $200 \mathrm{~m}$ and vertically stretched levels with varying distances of $12 \mathrm{~m}$ near the ground to $75 \mathrm{~m}$ higher aloft. In Wagner et al. (2014a) it is shown that high-resolution simulations with $200 \mathrm{~m}$ for similar valley setups as in this study are in very good agreement with corresponding simulations with horizontal mesh sizes of $100 \mathrm{~m}$. This enables to use a horizontal grid spacing of $200 \mathrm{~m}$ for LES-like simulations in this study. The integrating time step is $2.0 \mathrm{~s}$. The model top is set to $8 \mathrm{~km}$ with a Rayleigh damping layer covering the uppermost $2000 \mathrm{~m}$. In the alongvalley direction solid-wall and in the cross-valley direction periodic lateral boundary conditions are applied resulting in repeating parallel valleys.

All simulations are initialized with an atmosphere at rest, a constant vertical gradient of potential temperature of $3 \mathrm{~K} \mathrm{~km}^{-1}$ and a potential temperature of $297 \mathrm{~K}$ at a pressure of $1000 \mathrm{hPa}$. A moist-unsaturated atmosphere with a constant relative humidity of $40 \%$ at the beginning of the simulations is chosen. The surface roughness is set to $0.16 \mathrm{~m}$ and the thermal forcing is defined by a spatially constant, but time-dependent surface sensible heat flux (HFX) according to Rampanelli et al. (2004):

$\mathrm{HFX}=\mathrm{HFX}_{\max } \sin (\omega t)$,

with time $t$, maximum surface heat flux $\mathrm{HFX}_{\max }=150 \mathrm{~W} \mathrm{~m}^{-2}$ and angular velocity of the Earth $\omega=2 \pi /(24 \mathrm{~h})$. In order to trigger convection at the beginning of the simulation, randomly distributed potential temperature perturbations with an amplitude of $0.5 \mathrm{~K}$ are added to the five lowermost model levels. All simulations are run for $12 \mathrm{~h}$ with a maximum surface heat flux forcing after $6 \mathrm{~h}$. The averaging of the LES flow variables is performed according to the method of Schmidli (2013) and described in Wagner et al. (2014a). Additional averaging is labelled with [ ] for along-valley, [ $]_{x, y}$ for along- and cross-valley, []$_{V}$ for valley volume and [ $]_{V, t}$ for valley volume and time averaging, respectively.

Different sensitivity runs are performed to study the impact of an inclined valley floor and a narrowing valley cross section on the developing flow. A straight valley with a flat valley floor and a valley width of $20 \mathrm{~km}$ is used as reference run (REF, see Table 1). The inclination of the valley floor is then varied from 0.375 to $1.5 \%$ (cases I0_375 to I1_5), which corresponds to floor angles between $0.21^{\circ}$ and $0.86^{\circ}$. These angles correspond to average valley floor inclinations of valleys in the European Alps like the lower Inn Valley between Kufstein and Innsbruck $\left(0.05^{\circ}\right)$, the Isar Valley between Bad Tölz and Lake Sylvenstein $\left(0.29^{\circ}\right)$, the Wipp Valley between Innsbruck and Brenner pass $\left(0.6^{\circ}\right)$, or the Oetz Valley between Oetz and Sölden $\left(1.0^{\circ}\right)$. Narrowing valleys are defined by increasing the valley width at the valley entrance $(y=0 \mathrm{~km})$ to 30 or $40 \mathrm{~km}$ (as in the $\mathrm{W} 30$ or W40 cases, respectively) and by keeping the valley width at the end of the valley $(y=100 \mathrm{~km})$ at $20 \mathrm{~km}(\mathrm{~W} 30 \mathrm{~N}$ and $\mathrm{W} 40 \mathrm{~N})$. A combination of inclined valley floor and narrowing valley width is used in the W30NI and W40NI cases. The size of the flat foreland is equal in all valley-plain topographies. In addition, a flat plain simulation (PLAIN) with a developing convective boundary layer without valley topography and a plain-slope simulation (SL) with a flat foreland and an adjacent slope with an inclination of $0.86^{\circ}$ (as in the I1_5 case) are performed in a domain with the same size as the REF simulation. The SL case is used to separate valley volume from slope wind effects, as an imaginary box over the valley region in the SL run between $-10 \mathrm{~km} \leq x \leq 10 \mathrm{~km}$, $0 \mathrm{~km} \leq y \leq 100 \mathrm{~km}$ and $0 \mathrm{~km} \leq z \leq 1.5 \mathrm{~km}$ has the same volume as the valley volume of the REF case. The volume of a corresponding box over a flat plain is twice as large as the valley volume of the REF case. An overview of the terrain parameters is given in Table 1 and the topographies of the REF, I1_5, W40N and W40NI cases are shown in Fig. 1.

To investigate the amplification of vertical transport over valleys compared to a flat plain, both mass flux budgets of the valley volume and forward trajectory analyses are performed. As in Wagner et al. (2014a) three boundary layer 

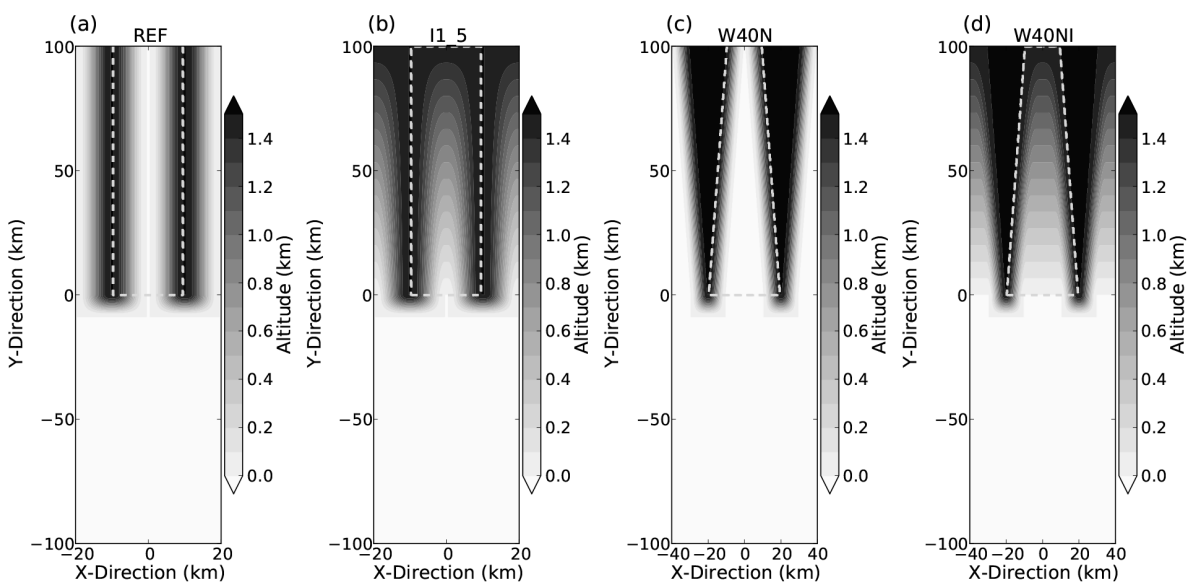

Figure 1. Modelling domain and valley topography for (a) REF, (b) I1_5, (c) W40N and (d) W40NI simulations. The dashed grey boxes mark the horizontal areas at crest height, which define the upper surface of a box that is used for computations of valley volume mass flux budgets and valley volume averages of along-valley wind speed.

heights are defined: a lower and upper mixed layer height and an entrainment layer height. The mixed layer heights are determined as the altitudes where the potential temperature gradient reaches a value of $0.001 \mathrm{~K} \mathrm{~m}^{-1}$ (see Catalano and Moeng, 2010) when moving upward from the surface (PBL1) and downward from the model top (PBL2). The entrainment layer height (PBL3) is defined as the altitude of the maximum potential temperature gradient (see Schmidli, 2013). The spatial averages over the whole modelling domain of the three boundary layer heights of the PLAIN simulation are used as reference heights for trajectory analyses in this study and are called PLAIN-PBL1, PLAIN-PBL2 and PLAIN-PBL3, respectively. See Fig. 2 for the evolution of PLAIN-PBL reference heights and Wagner et al. (2014a) for more details on the determination of the boundary layer heights.

\section{Results}

\subsection{Flow evolution}

The flow evolution of the REF case is identical to the results of the reference run in Wagner et al. (2014a). Over the foreland a convective boundary layer and a plain-to-mountain circulation develops in all simulations using a valley-plain topography. In the valley upslope and upvalley winds establish, which become strongest during the local afternoon of the simulations (not shown). The instantaneous along-valley flow at $100 \mathrm{~m}$ above ground level (AGL) is displayed in Fig. 3 for the REF, I1_5, W40NI and SL cases. In the REF run wind speeds are strongest in the valley near the valley entrance region and become relatively weak further upvalley. Upvalley winds penetrate up to 80 and $90 \mathrm{~km}$ into the valley after 6 and $10 \mathrm{~h}$ of simulation in the REF run (as a threshold to detect the penetrating wind, a mean along-valley wind larger than $0.2 \mathrm{~m} \mathrm{~s}^{-1}$ is used). In the I1_5 and W40NI cases, how-

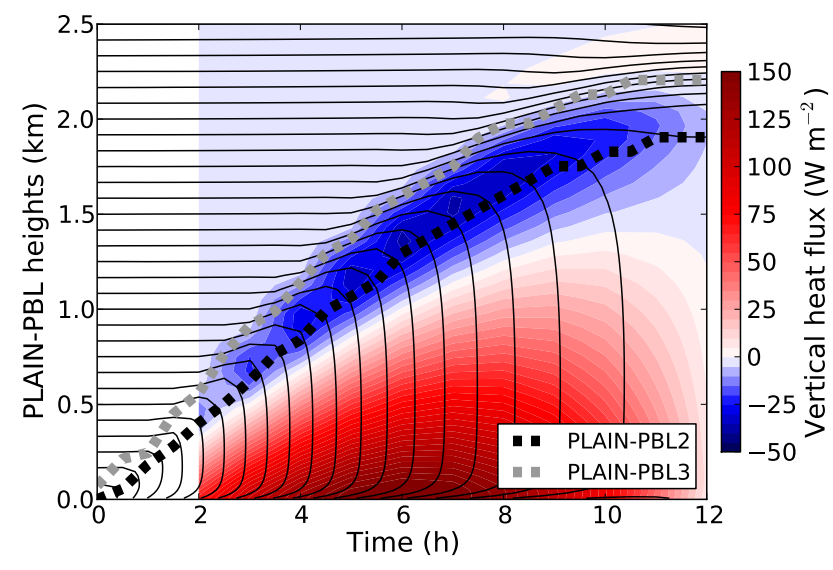

Figure 2. Evolution of mean boundary layer heights of the PLAIN simulation. Two different boundary layer height definitions are shown: PLAIN-PBL2 (black dotted line) is determined by a potential temperature gradient threshold of $0.001 \mathrm{~K} \mathrm{~m}^{-1}$, whereas PLAIN-PBL3 (grey dotted line) is defined by the height of the maximum potential temperature gradient (see text). Thin contour lines and colour shading show horizontally averaged potential temperature (contour interval: $0.25 \mathrm{~K}$ ) and total vertical heat flux profiles $\left(\mathrm{W} \mathrm{m}^{-2}\right)$ of the PLAIN simulation, respectively. Values for vertical heat fluxes are not available during the first $2 \mathrm{~h}$ of simulation due to time averaging technical reasons. Adopted from Wagner et al. (2014a).

ever, maximum upvalley winds are located in the middle of the valley and are more constant in the along-valley direction. The SL case exhibits quite constant upslope wind speeds over the slope, but relatively weak winds at the slope start point $(y=0 \mathrm{~km})$ due to the absence of mountain ridges.

The temporally averaged flow fields are spatially averaged on constant model levels in the along-valley direction between $5 \mathrm{~km} \leq y \leq 15 \mathrm{~km}$, i.e. in the valley entrance region, 

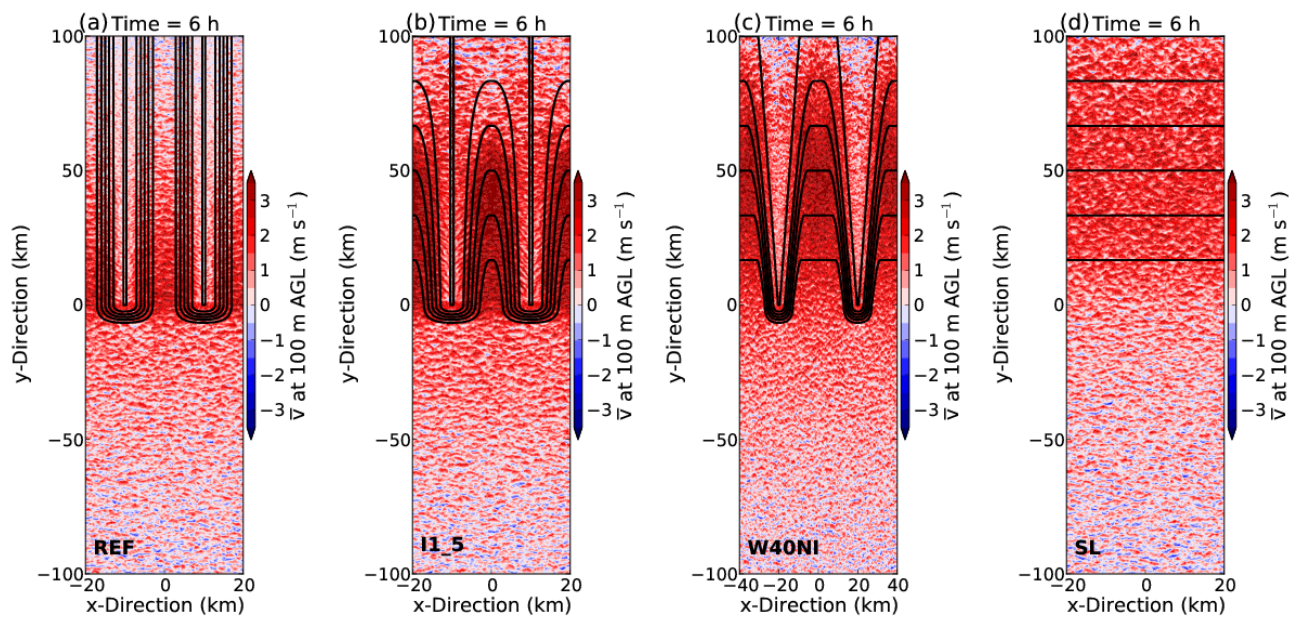

Figure 3. Instantaneous along-valley flow at $100 \mathrm{~m}$ AGL after $6 \mathrm{~h}$ of simulation for (a) REF, (b) I1_5, (c) W40NI and (d) SL simulation. Black contour lines show the topography with intervals of $0.25 \mathrm{~km}$. The lowermost topography contour line is set to $0.25 \mathrm{~km}$.

and shown as cross sections after $6 \mathrm{~h}$ of simulation in Fig. 4 . The PLAIN simulation develops a convective boundary layer with mixed layer heights (PBL1, PBL2) at about $1.3 \mathrm{~km}$ and an entrainment layer height (PBL3) at about 1.5 to $1.6 \mathrm{~km}$ AGL. In the reference run a valley inversion layer separates two vertically stacked cross-valley circulation cells with a lower mixed layer height (PBL1) below and an upper mixed layer height (PBL2) above mountain crest height. Alongvalley winds exceed $2 \mathrm{~m} \mathrm{~s}^{-1}$ within the valley and reach values of about $1.2 \mathrm{~m} \mathrm{~s}^{-1}$ in the mountain-to-plain return flow aloft.

An inclination of the valley floor by an angle of $0.86^{\circ}$ (I1_5) significantly increases the upvalley wind speed to values larger than $3 \mathrm{~m} \mathrm{~s}^{-1}$. The valley inversion layer is slightly stronger than in the REF simulation. Increased valley widths cause much weaker upvalley flows than in the reference case (see the W40 simulation in Wagner et al., 2014a). A reduction of valley width from $40 \mathrm{~km}$ at the valley entrance region to $20 \mathrm{~km}$ at the valley end (W40N) nearly doubles the upvalley wind speeds from about $0.6 \mathrm{~m} \mathrm{~s}^{-1}$ (W40) to about $1.2 \mathrm{~m} \mathrm{~s}^{-1}(\mathrm{~W} 40 \mathrm{~N})$. Further increase of the upvalley flow is attained by tilting the floor of the narrowing valley $\mathrm{W} 40 \mathrm{~N}$ by an angle of $0.86^{\circ}$ (W40NI), which results in upvalley winds larger than $2 \mathrm{~m} \mathrm{~s}^{-1}$.

To demonstrate differences in the upvalley flow due to inclined valley floors and narrowing valley widths, alongvalley cross sections at the valley centre $(x=0 \mathrm{~km})$ are displayed in Fig. 5. In all simulations the mixed layer heights PBL1 and PBL2 are identical over the foreland and split up into a lower and an upper mixed layer height over the valley region. The strong increase of the boundary layer depth over the valley compared to the foreland is clearly visible by the PBL2 and PBL3 heights. The valley inversion layer separates the upvalley flow near the surface from a mountain-to-plain return flow aloft. The upvalley wind becomes stronger the steeper the valley floor is inclined (see Fig. 5a-c) due to the additional upslope buoyancy force and the smaller valley volume (see Table 1). The latter results in stronger heating and thus stronger along-valley pressure gradients. Along-valley wind speeds are also increased by narrowing valley widths (see W40N). In combination with an inclined valley floor, upvalley winds of the W40NI case become even stronger than in the reference case (REF).

Along-valley wind speed averages over the whole valley volume are shown as time series in Fig. 6a and demonstrate the increase of upvalley winds due to inclined valley floors and narrowing valley cross sections. Relatively weak valley mean along-valley wind speeds in the REF case are due to low wind speeds in the upper part of the valley (e.g. in regions for $y>40 \mathrm{~km}$, see Fig. 3), whereas simulations with inclined floors and narrowing valley cross sections exhibit more constant wind speeds in along-valley direction.

Time averaging between 6 to $10 \mathrm{~h}$ of valley volumeaveraged wind speeds allows us to distinguish between slope, narrowing and valley volume effects (Fig. 6b). The averaging interval between 6 to $10 \mathrm{~h}$ is chosen, as wind speeds show a relatively constant increase in all simulations during this time (see Fig. 6a). The following amplification effects can be determined:

- The slope wind effect for a tilted valley floor of $0.86^{\circ}$ increases upvalley winds by a factor of about 1.6. This factor is obtained when comparing the SL case with the REF case, which have both the same "valley" volume but inclined and flat valley floors, respectively.

- The narrowing effect reveals an amplification of the valley wind by a factor of about 2.6, which is derived by comparing the W30 and W40N cases, which have the same valley volume and only differ in the narrowing valley cross section. 

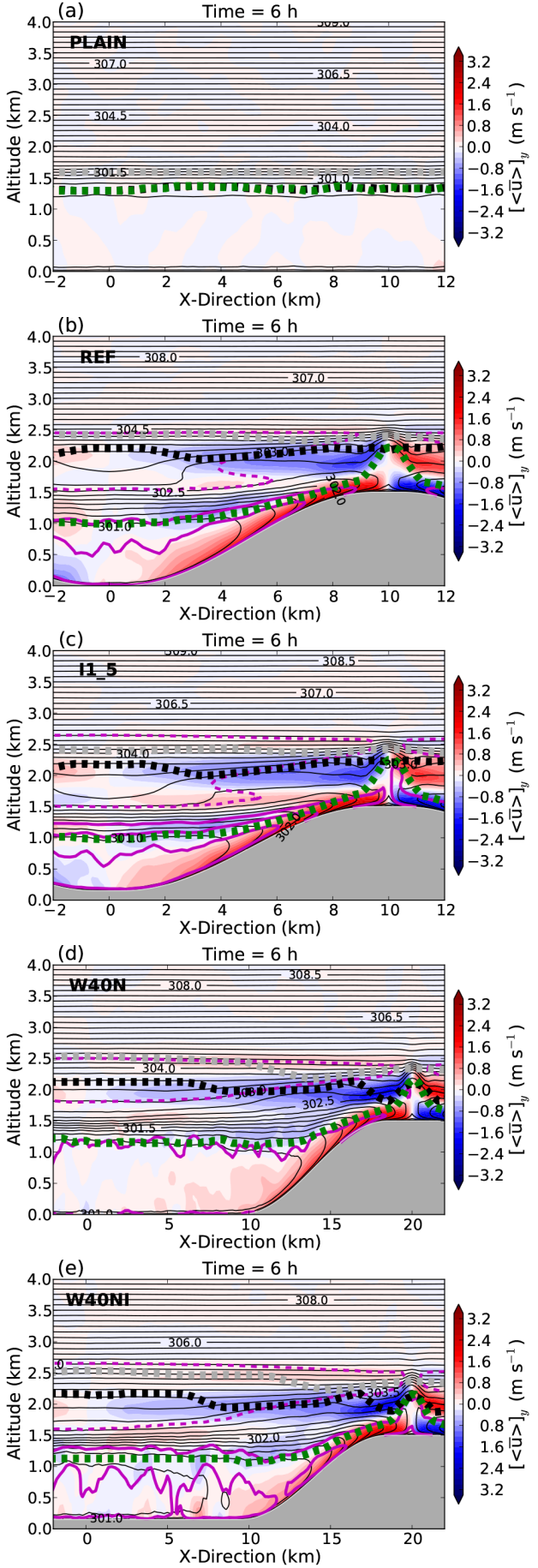

Figure 4. Cross sections of potential temperature (thin contour lines, interval: $0.25 \mathrm{~K}$ ), cross-valley (colour shading) and alongvalley wind speed (thick magenta contour lines, negative values dashed, interval $1.0 \mathrm{~m} \mathrm{~s}^{-1}$, the zero line is not shown) averaged between $y=5$ and $y=15 \mathrm{~km}$ after $6 \mathrm{~h}$ of simulation. Topographies correspond to locations at $y=10 \mathrm{~km}$. Boundary layer heights PBL1, PBL2 and PBL3 are plotted with thick dashed green, black and grey lines, respectively.
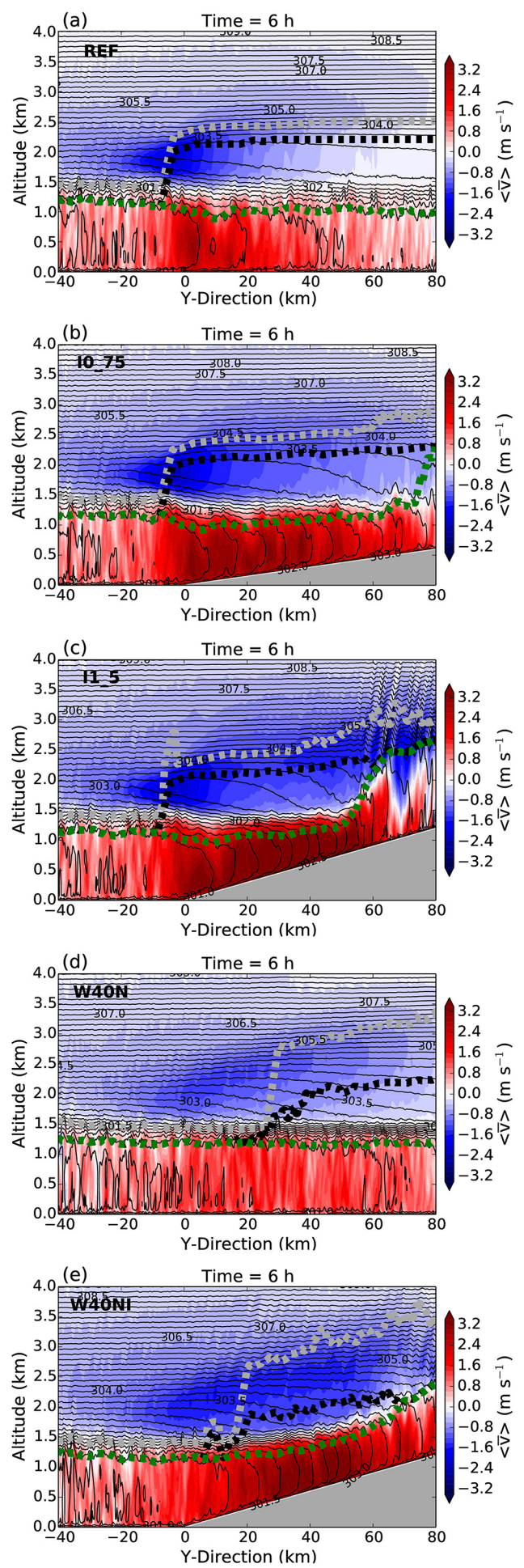

Figure 5. Temporally averaged along-valley flow (colour shading) and potential temperature (contour lines, interval: $0.25 \mathrm{~K}$ ) after $6 \mathrm{~h}$ of simulation at $x=0 \mathrm{~km}$ for different valley depths and widths. Boundary layer heights PBL1, PBL2 and PBL3 are plotted with thick dashed green, black and grey lines, respectively. 

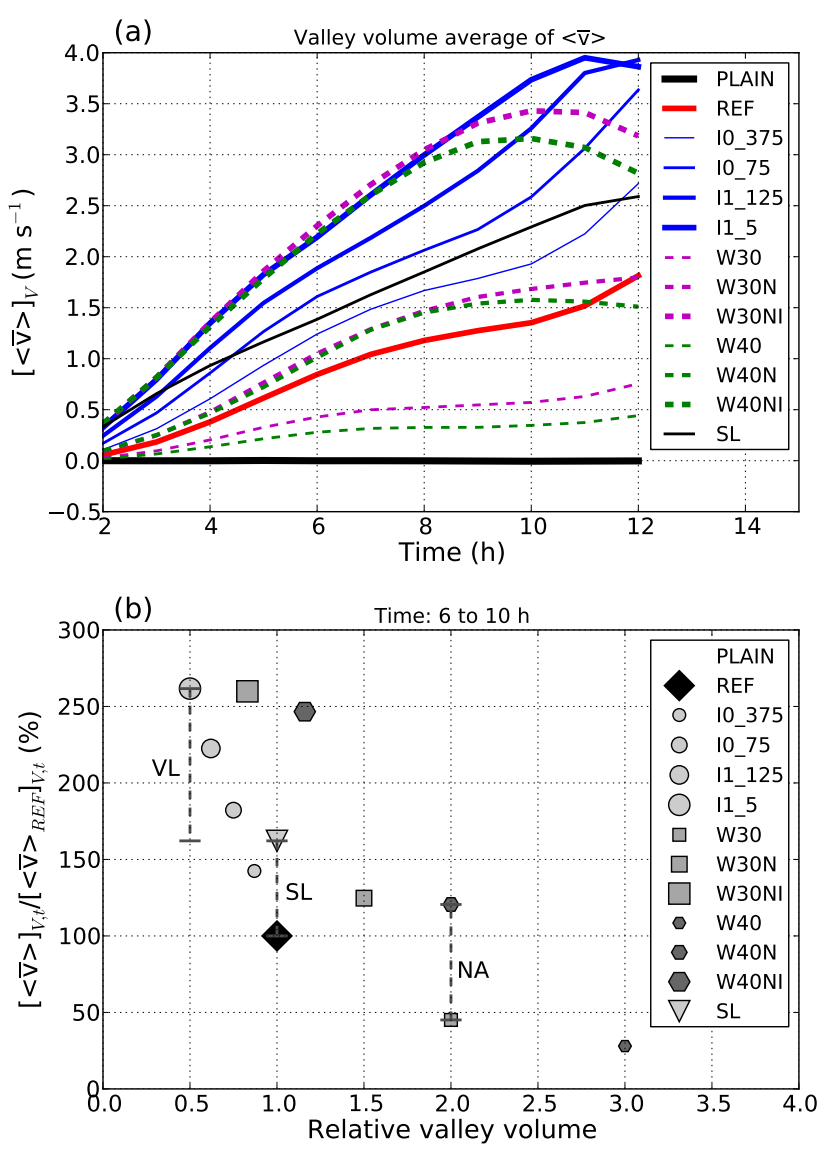

Figure 6. Valley volume averages of upvalley wind speed. (a) Time series and (b) time average between 6 and $10 \mathrm{~h}$ of simulation of mean valley volume upvalley winds. Values in (b) are scaled with the REF case. The vertical dashed lines mark the amplification due to the valley volume effect (VL, factor 1.9), the slope effect (SL, factor 1.6; for an inclination angle of $0.86^{\circ}$ ) and the narrowing effect (NA, factor 2.6; for a reduction of the valley cross section by $20 \mathrm{~km}$ per $100 \mathrm{~km}$ along-valley distance), see text for details.

- Reducing the valley volume by $50 \%$ yields an amplification factor for upvalley winds between 1.6 and 2.2 (1.9 on average). This can be obtained when comparing the I1_5 and the SL cases (factor 1.6) or the REF and W30 cases (factor 2.2).

Combining these effects by multiplying the single factors shows good agreement with the simulated amplification factors. For example, comparing the $\mathrm{W} 40$ and $\mathrm{W} 30 \mathrm{~N}$ cases results in a theoretical amplification factor of $4.9(1.9 \times 2.6)$ due to the valley volume and the narrowing effect, which is close to the simulated value of 4.5. The comparison of the REF case with the I1_5 case results in a value of 3.0 $(1.9 \times 1.6)$ due to the valley volume and the slope effect, which is in good agreement with the simulated value of 2.6.

Along-valley structures in the valley centre $(x=0 \mathrm{~km})$ of potential temperature, pressure and along-valley wind speed are shown in Fig. 7 after $6 \mathrm{~h}$ of simulation at a constant alti- tude of $0.7 \mathrm{~km}$, which is well below the valley inversion layer (thus intersecting with the terrain for the cases with inclined valley floors). Over the foreland the same potential temperature develops in all simulations, whereas potential temperatures vary by up to $2.5 \mathrm{~K}$ in the valley (Fig. 7a). Due to the smaller valley volume (see Table 1), the temperature increase in the valley is stronger the steeper the valley floor is chosen (e.g. I1_5). Higher temperatures in the valley lead to a stronger pressure gradient between the foreland and the valley region (Fig. 7b). According to the temperature contrast in Fig. 7a, the pressure gradients are strongest for smaller valley volumes. Wind speeds remain relatively constant from the valley mouth up to about 30 to $40 \mathrm{~km}$ into the valley if the valley floor is inclined (e.g. I0_375, I0_75, see Fig. 7c), whereas the REF run shows a sharp peak at the valley entrance $(y=0 \mathrm{~km})$ due to the strong temperature increase in this region and nearly constant temperatures within the valley (see Fig. 7a and Fig. 3). In spite of large differences in temperature, pressure and along-valley wind speeds in the valley among the simulations, upvalley wind speeds correlate quite well with along-valley pressure gradients in $0.7 \mathrm{~km}$ height (Fig. 7d). A similar figure can be found in Vergeiner and Dreiseitl (1987) thus demonstrating the equilibrium of pressure gradient force and turbulent friction:

$\frac{\mathrm{d} v}{\mathrm{~d} t}+\frac{1}{\rho} \frac{\partial p}{\partial y}=-k v$,

with along-valley wind speed $v$, air density $\rho$, pressure $p$ and Guldberg-Mohn type friction coefficient $k$ (see Eq. 15 in Vergeiner and Dreiseitl, 1987). The computation of the linear friction coefficient $k$ by neglecting advection $(\mathrm{d} u / \mathrm{d} t \approx$ $\partial u / \partial t)$ and assuming quasi-stationary conditions yields a value of $(2317 \mathrm{~s})^{-1}$ or a relaxation time of $1 / k=39 \mathrm{~min}$, which is nearly identical to the value of $k=(2700 \mathrm{~s})^{-1}$ in Vergeiner and Dreiseitl (1987).

Mean vertical profiles of potential temperature and alongvalley wind speed over the foreland and the valley entrance region are shown in Fig. 8. As in Wagner et al. (2014a) averaging is done along constant height levels by interpolating relevant variables on a Cartesian grid. Horizontal averaging over the foreland is done between $-20 \mathrm{~km} \leq y \leq 0 \mathrm{~km}$ and over the valley entrance region between $0 \mathrm{~km} \leq y \leq 20 \mathrm{~km}$. In cross-valley direction the extent of the averaging region is defined between the mountain crests (e.g. $x=-10$ to $10 \mathrm{~km}$ for the REF case and $x=-20$ to $20 \mathrm{~km}$ for the W40, $\mathrm{W} 40 \mathrm{~N}$ and W40NI cases). Over the foreland all simulations show similar thermal structures, which are typical for a convective boundary layer over flat terrain. The profiles are identical if averaging is done over the whole foreland (i.e. $-100 \mathrm{~km} \leq y \leq 0 \mathrm{~km}$ ). In the valley a three-layer thermal structure (Vergeiner et al., 1987; Schmidli, 2013; Wagner et al., 2014b, a) with a valley inversion below crest height develops in all valley-plain simulations. Highest temperatures develop in cases with small valley volumes (e.g. I1_5). Profiles of along-valley wind speed over the foreland show a 

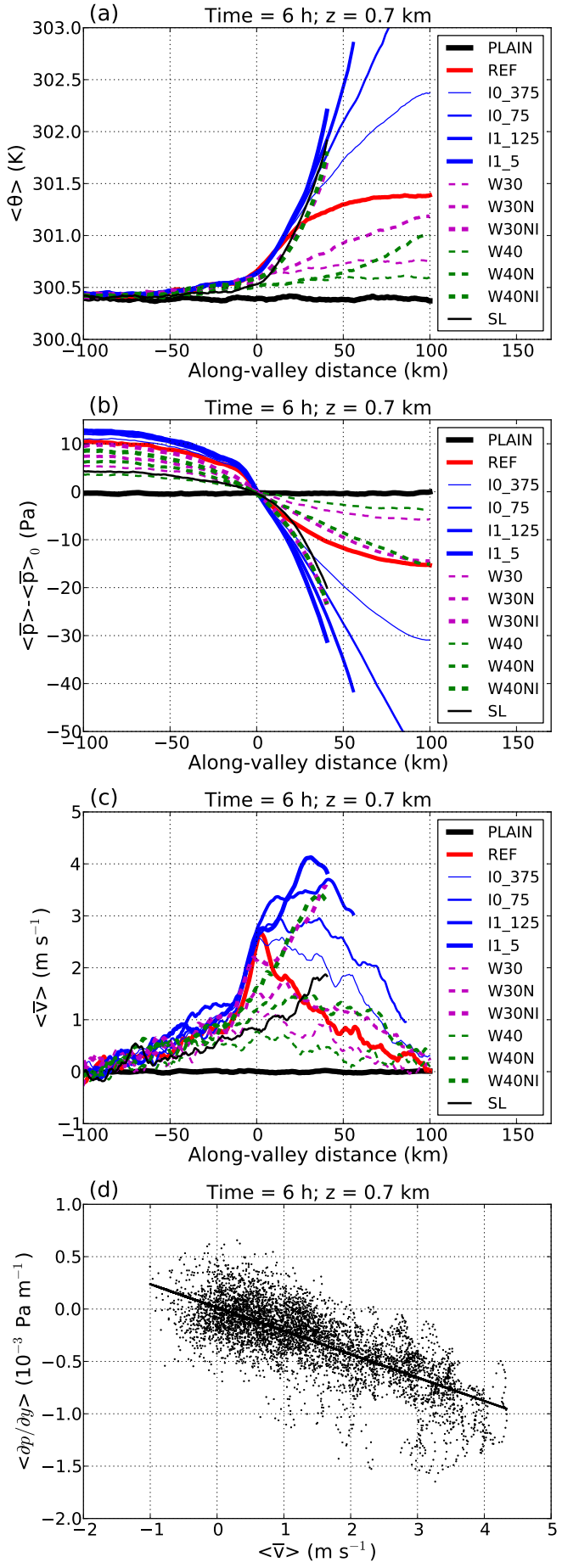

Figure 7. Along-valley structures at $0.7 \mathrm{~km}$ altitude in the valley centre $(x=0 \mathrm{~km})$ after $6 \mathrm{~h}$ of simulation of (a) potential temperature, (b) pressure deviation from pressure at the valley entrance $(y=0 \mathrm{~km})$ and (c) along-valley wind speed. Running average smoothing with an interval of $5 \mathrm{~km}$ is applied to all curves. The correlation of along-valley wind speed and along-valley pressure gradient is plotted for points in the valley ( $x=0 \mathrm{~km}, y>0 \mathrm{~km})$ for all simulations in (d). The black line marks a linear fit of all points.
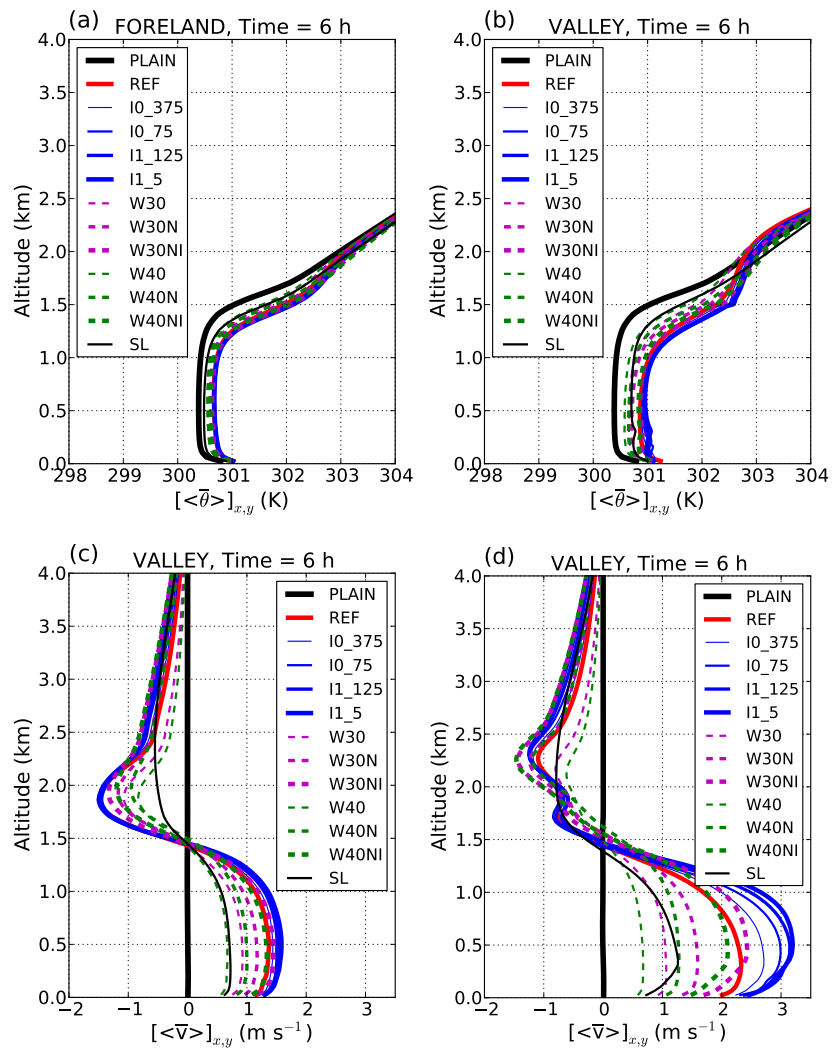

Figure 8. Mean vertical profiles of (a) and (b) potential temperature and (c) and (d) along-valley wind speed over the foreland $(-20 \mathrm{~km}<y<0 \mathrm{~km}$; left $)$ and the valley entrance region $(0 \mathrm{~km}<$ $y<20 \mathrm{~km}$; right) after $6 \mathrm{~h}$ of simulation. In cross-valley direction the extent of the averaging region is defined between the mountain crests.

plain-to-mountain flow below crest height and a return flow aloft, which is strongest for cases with small valley volumes. Along-valley winds near the valley entrance in the valley are strongest for simulations with inclined floors (e.g. I1_5). In the SL case wind speeds at the foot of the slope are relatively weak and become stronger further upslope at $y>20 \mathrm{~km}$ due to the absence of mountain ridges (see Fig. $3 \mathrm{~d}$ ).

\subsection{Mass flux budget analysis}

In order to investigate the influence of along-valley terrain heterogeneity on horizontal and vertical transport processes, mass fluxes into and out of the valleys are computed. Due to solid-wall boundary conditions in along-valley direction, only two surfaces of the valley volume have to be considered: horizontal mass fluxes through the valley entrance at $y=0 \mathrm{~km}$ and vertical mass fluxes out of the valley at ridge top height. The valley entrance region (at $y=0 \mathrm{~km}$ ) is limited by the mountain ridges in cross-valley direction and by the mountain crest height $(1.5 \mathrm{~km})$ in vertical direction. The 
horizontal extent of the valley volume boxes is shown in Fig. 1.

Time series of mean mass fluxes into $(>0)$ and out $(<0)$ of the valley volumes are shown in Fig. 9a and b. Mass fluxes (per unit area) into the valley are 2 orders of magnitude larger than mass fluxes out of the valley due to stronger horizontal winds and a smaller cross section at the valley entrance compared to vertical motions at the valley top. Integration of the horizontal and vertical mass fluxes over the two corresponding areas yields equal total exchanged mass $\left(\mathrm{kg} \mathrm{s}^{-1}\right)$ into and out of the valley for each simulation, as expected from the principle of mass conservation (Fig. 9c). The inspection of simulations with equal valley cross sections at the valley entrance (e.g. REF and I1_5) demonstrates increased mass fluxes in simulations with inclined valley floors due to stronger upvalley winds at $y=0 \mathrm{~km}$ (see also Fig. 8d). The comparison of time averages over the last $6 \mathrm{~h}$ of simulation of vertical mass fluxes out of the valley volume of REF and I1_5, W30N and W30NI, or W40N and W40NI reveals a mass flux amplification factor due to inclined valley floors of 1.2. A stronger mass flux increase is induced by narrowing valley cross sections, as can be obtained by comparing W30 with W30N and W40 with W40N, which yields amplification factors of 1.8 and 2.8, respectively (Fig. 9d).

\subsection{Trajectory analysis}

To investigate the effect of along-valley terrain heterogeneity on transport processes in the boundary layer, out of the valley and into the free atmosphere, forward trajectories are computed for all simulations by using the post-processing tool Read-Interpolate-Plot (RIP), version 4.4 (Stoelinga, 2009). The trajectory computations are based on instantaneous model wind fields, which are available every $5 \mathrm{~min}$ and use a trajectory time step of $2.5 \mathrm{~min}$. Note that a trajectory calculation based on a 5 min interval does not include effects of subgrid-scale turbulent diffusion, but can be used to investigate transport processes of mesoscale flows, such as upslope and upvalley winds in this study. It can be expected that including the turbulent diffusion contribution would "blur" the results to some extent but not entirely reverse the proportions. Turbulent transport was shown to significantly contribute to total exchange of heat only very close to the surface and to some extent at crest height (Wagner et al., 2014a). As in Wagner et al. (2014a), 1764 trajectories are initialized in a box with a horizontal extent of $4 \times 4 \mathrm{~km}$ and on levels of 25,50 , 75 and $100 \mathrm{~m}$ AGL. To keep the box-width to valley-width ratio of 0.2 constant, the box width is increased to 6 and $8 \mathrm{~km}$ for the W30 and W40 simulations, respectively. The box is centred at $x=0 \mathrm{~km}$ and at different along-valley positions of $y=-10 \mathrm{~km}$ and $+10 \mathrm{~km}$ and all trajectories are calculated for $12 \mathrm{~h}$. In contrast to the mass flux analyses, where a fixed area at mountain crest height is used as reference surface, the time-dependent mean boundary layer heights of the PLAIN simulation (PLAIN-PBL2, PLAIN-PBL3) are chosen as ref- erence heights to separate parcels within the boundary layer from parcels in the free atmosphere.

Figure 10 shows pathways of parcels started $10 \mathrm{~km}$ in front of the valley entrance for the REF, I1_5, W40N and W40NI simulations. In the reference case parcels are transported up to $60 \mathrm{~km}$ into the valley and are advected to altitudes far above the mountain crests by upslope winds and convective cells. They are then captured by the return flow and transported up to $40 \mathrm{~km}$ back over the foreland. The horizontal transport is strongly increased in the I1_5 case due to the stronger upvalley winds in the valley. A significant number of parcels penetrate more than $80 \mathrm{~km}$ into the valley. The number of parcels above the PLAIN-PBL2 reference height is, however, very similar to the REF case. Narrowing the valley width also increases the horizontal transport. In the W40 case (not shown) parcels are transported up to $20 \mathrm{~km}$ into the valley, whereas they reach $40 \mathrm{~km}$ in the W40N case (Fig. 10c). The combination of narrowing valley widths and an inclined valley floor (W40NI) further increases the alongvalley transport and parcels penetrate nearly $80 \mathrm{~km}$ into the valley. This is nearly $20 \mathrm{~km}$ deeper than in the reference case (REF), where most parcels are transported upwards by upslope winds. This vertical transport is lower in wide valleys (e.g. W40, W40N, W40NI), as most parcels are located far away from the slopes and cannot be captured by slope winds. An enlargement of the trajectory start box over the whole valley width in the cross-valley direction increases the vertical transport in both narrow and wide valleys, as more parcels reach the slopes (not shown). The number of parcels which are transported to altitudes above the reference boundary layer height PLAIN-PBL2 is, however, significantly higher for narrow valleys compared to wide valleys. This means that for both the small- and large-trajectory start boxes vertical transport of parcels above PLAIN-PBL2 is about 5 and 2 times stronger, respectively, when comparing the REF and W40NI cases. Thus it seems that the relative enhancement is quite robust even if the absolute extent of the vertical exchange is, of course, a function of size and location of the start box.

The evolution of height and along-valley distribution of the parcels is shown in Figs. 11 and 12 for trajectories started in the valley at $y=10 \mathrm{~km}$. In the PLAIN simulation nearly all parcels stay below the entrainment layer height (PLAINPBL3, Fig. 11a). Nearly all parcels reside at their initial along-valley position $(y=10 \mathrm{~km})$ with only weak horizontal dispersion towards the simulation end due to the lack of a directed flow in the convective boundary layer (Fig. 12a). In the REF run most of the parcels are transported towards the mountain ridges by upslope flows and to altitudes far above crest height by convective cells during the first $4 \mathrm{~h}$. The majority of the parcels stay above the entrainment layer height PLAIN-PBL3 during the first $6 \mathrm{~h}$ and above the mixed layer height PLAIN-PBL2 until the end of the simulation (Fig. 11b). After the vertical transport to high altitudes most parcels are captured by the return flow and are advected more 

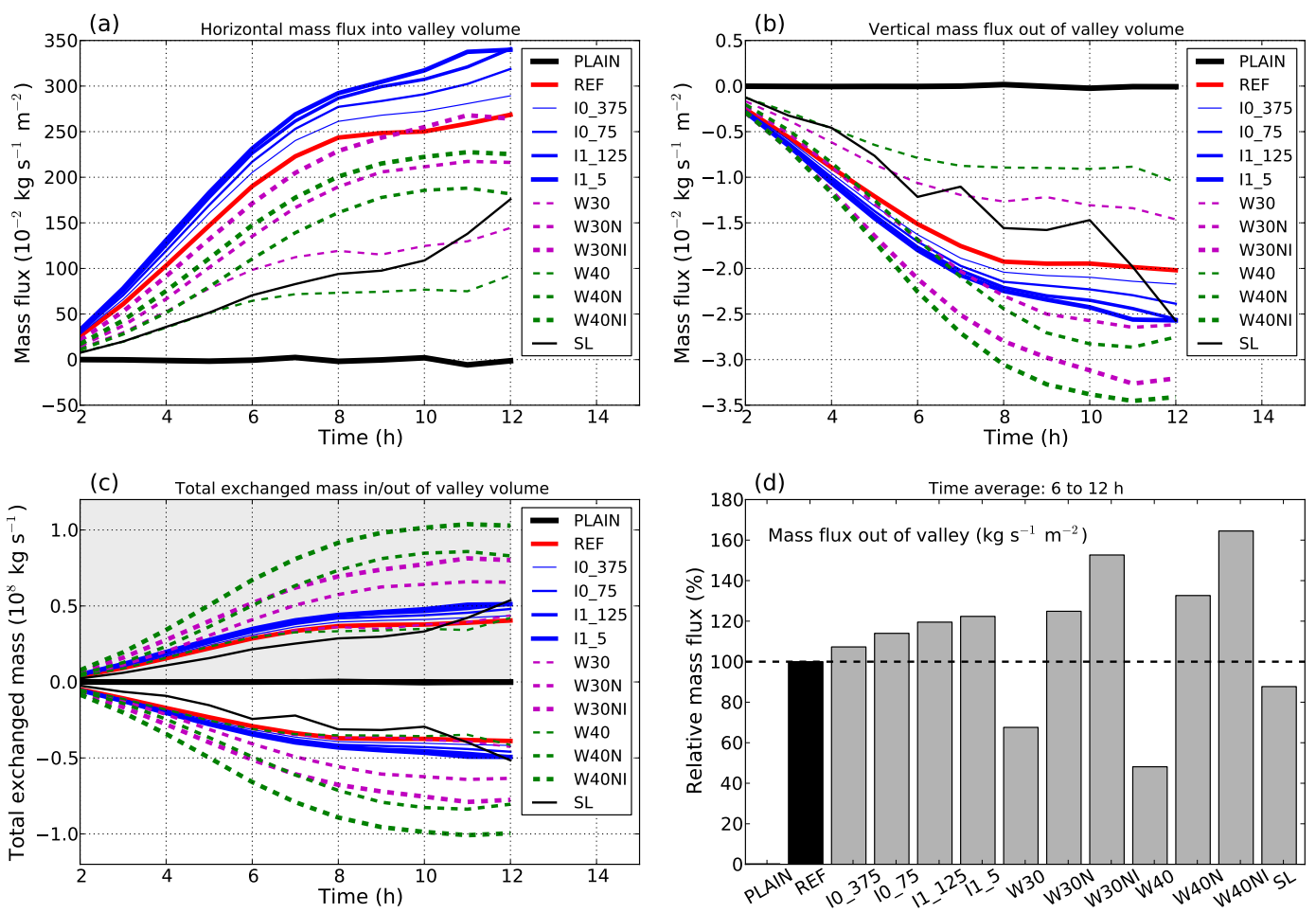

Figure 9. Mean mass flux budget of the whole valley volume, which is limited by the vertical cross section at the valley entrance $(y=0 \mathrm{~km}$, $0 \leq z \leq 1.5 \mathrm{~km})$ and the horizontal area at crest height $(0 \leq y \leq 100 \mathrm{~km}$, see Fig. 1). Negative values imply mass fluxes out of the volume. (a) Time series of horizontal mass flux $\left(\mathrm{kg} \mathrm{s}^{-1} \mathrm{~m}^{-2}\right)$ into and (b) vertical mass flux $\left(\mathrm{kg} \mathrm{s}^{-1} \mathrm{~m}^{-2}\right)$ out of the valley volume. (c) Total exchanged mass (i.e. $\mathrm{kg} \mathrm{s}^{-1}$ ) into (grey shaded area) and out (white shaded area) of the valley volume. (d) Relative mass fluxes out of the valley averaged between 6 and $12 \mathrm{~h}$ of simulation and scaled with the corresponding value of the REF case (black bar). The horizontal dashed line in (d) marks mass flux ratios of $100 \%$.

than $40 \mathrm{~km}$ over the foreland (Fig. 12b), whereas only a minor part is transported about $40 \mathrm{~km}$ into the valley by upvalley winds. Tilting the valley floor by $0.86^{\circ}$ (I1_5) does not significantly increase the vertical transport (see Fig. 11b and c) as most parcels are transported upwards by upslope winds at the beginning of the simulation, which is very similar to the REF case. Differences are, however, visible in the alongvalley transport, as in the I1_5 case parcels are transported slightly earlier and faster into the valley than in the REF case (see Fig. 12b and c). Narrowing the valley width does not increase the vertical transport of parcels, as most parcels are located at the valley floor far away from the upslope winds and the height distribution of the W40N case (Fig. 11d) is very similar to the W40 case (not shown, see Wagner et al., 2014a). In the W40N case the horizontal transport is, however, intensified due to stronger upvalley winds (see Fig. 8d), which is in agreement to mass flux analyses (Sect. 3.2). Tilting the valley floor in a narrowing valley (W40NI) increases the vertical transport compared to the W40 and W40N cases, especially towards the end of the simulation, when a large number of parcels has reached the plateau-like valley end. In the W40NI simulation most of the parcels remain near the valley floor while they are transported very far (up to $100 \mathrm{~km}$ ) into the valley (Fig. 11e and Fig. 12e).

To compare transport processes of all simulations, average positions of parcels are displayed in Figs. 13 and 14. Parcels which are started in the valley $(y=10 \mathrm{~km})$ are located above the mixed layer height PLAIN-PBL2 during the first $9 \mathrm{~h}$ of simulation in the REF run and in cases with inclined valley floors (I0_375 to I1_5, Fig. 13a). This means that inclined valley floors in straight valleys do not significantly increase the vertical transport of parcels started close to the surface. Note that mass flux computations used a different reference height (mountain crest height) and produced a mass flux amplification factor of 1.2 for valleys with inclined floors (see Sect. 3.2). Narrowing the valley width does also not increase the vertical transport of parcels from the valley floor significantly (see W30, W30N and W40, W40N, Fig. 13a). This seems to be in contrast to mass flux computations, which showed a mass flux amplification factor of 1.8 to 2.8 over narrowing valleys. However, the trajectory analysis is based on a thin layer of parcels started near the surface, whereas the mass flux budget analysis considers the whole air mass within the valley volume. The combination of narrowing the valley and tilting the valley floor causes, however, 

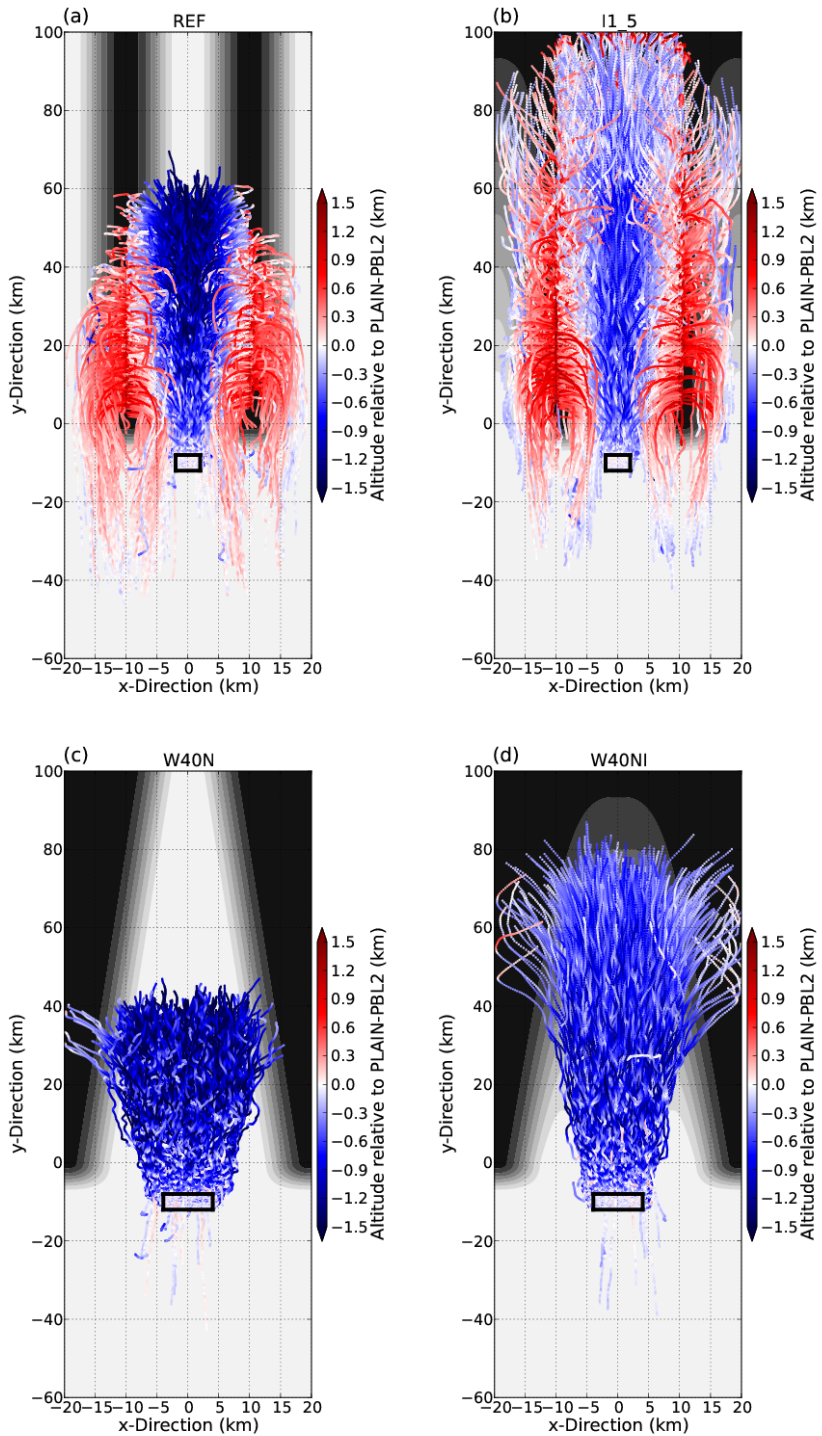

Figure 10. Trajectories started at the initial time of the simulations in a box centred at $x=0 \mathrm{~km}$ and $y=-10 \mathrm{~km}$ and computed for $12 \mathrm{~h}$ for (a) REF, (b) I1_5, (c) W40N and (d) W40NI cases. Trajectories are started at vertical levels of 25, 50, 75 and $100 \mathrm{~m}$ AGL in the region shown by the black box. The colour shading indicates the timedependent height of the trajectories. The time-dependent boundary layer height PLAIN-PBL2 (see Fig. 2) is used as reference height: blue colours denote parcels, which are located below this reference height, whereas red colours indicate parcels above PLAIN-PBL2.

a considerable increase in vertical transport compared to the PLAIN simulation, especially towards the end of the simulation. In these cases upvalley winds are strong enough to transport parcels from the surface towards the plateau at the valley end and then to altitudes above the PLAIN-PBL reference heights by convective cells.

In the REF case and in cases with inclined valley floors (I0_375 to I1_5) 80 to $90 \%$ and about 70 to $80 \%$ of the parcels are located above PLAIN-PBL2 and PLAIN-PBL3,
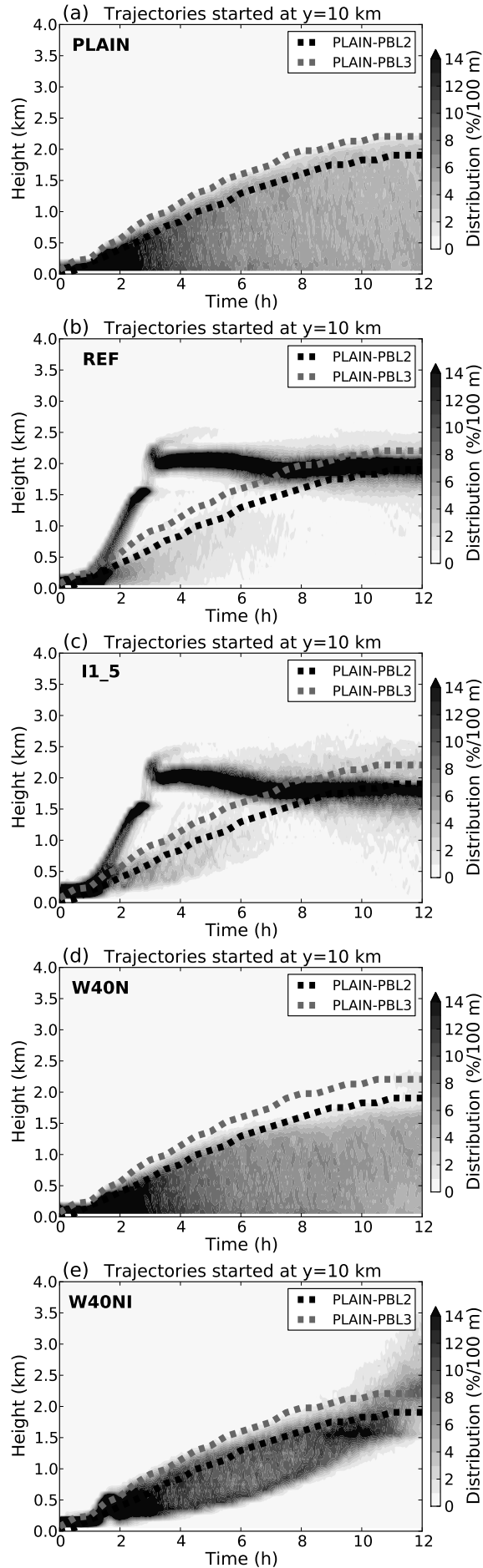

Figure 11. Evolution of parcel height distribution for trajectories started at $y=10 \mathrm{~km}$ for (a) PLAIN, (b) REF, (c) I1_5, (d) W40N and (e) W40NI simulation. The thick black and grey dashed lines mark the PLAIN-PBL2 and PLAIN-PBL3 height, respectively. Distribution values are calculated by splitting the vertical height column into bins of $100 \mathrm{~m}$ and determining the percentage of parcels within these height intervals $\left(\% 100 \mathrm{~m}^{-1}\right)$. 

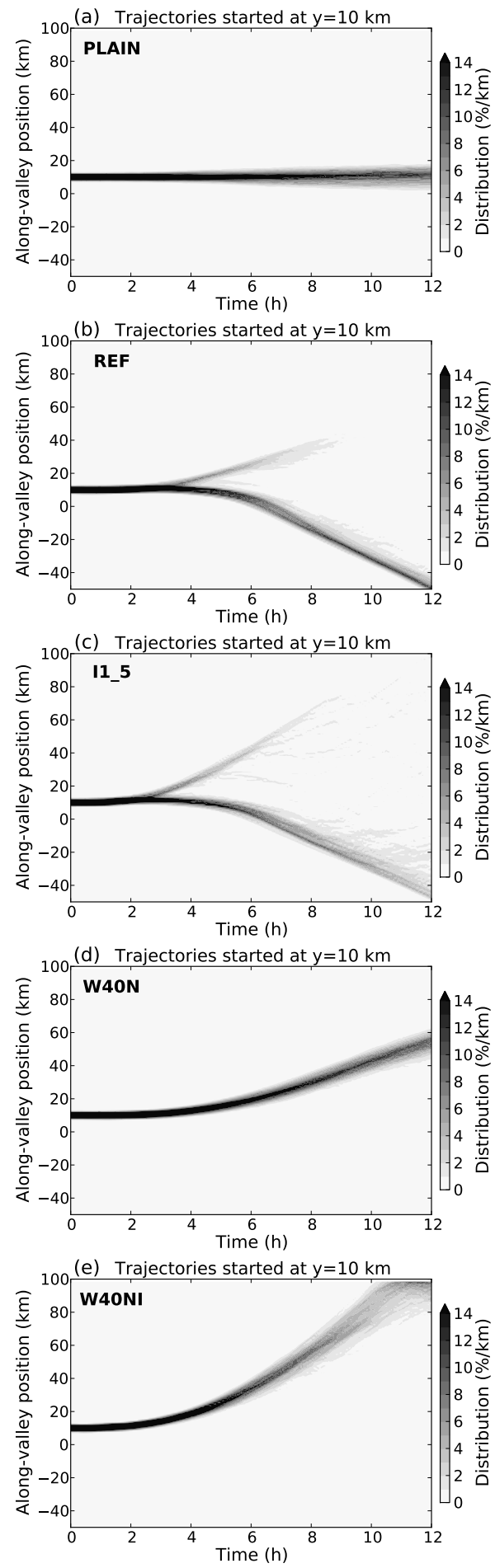

Figure 12. Evolution of parcel along-valley position distribution for trajectories started at $y=10 \mathrm{~km}$ for (a) PLAIN, (b) REF, (c) I1_5, (d) W40N and (e) W40NI simulation. Distribution values are calculated by splitting the along-valley distance into bins of $1 \mathrm{~km}$ and determining the percentage of parcels within these along-valley intervals $\left(\% \mathrm{~km}^{-1}\right)$. respectively, during the first 6 to $8 \mathrm{~h}$ (Fig. 13b, c). These numbers decrease towards the end of the simulation due to the growth of the PLAIN-PBL heights. In the PLAIN simulation and in wide and narrowing valleys (e.g. W40, W40N) only about $10 \%$ of the parcels are transported above PLAINPBL2 and nearly all parcels are located below PLAIN-PBL3, respectively. In narrowing valleys with inclined valley floors (W30NI, W40NI) the number of parcels above the reference heights increases to up to 85 and $75 \%$ (PLAIN-PBL2) and 65 and $55 \%$ (PLAIN-PBL3), respectively, towards the simulation end. Tilted valley floors and narrowing valley widths mostly influence the along-valley transport (Fig. 13d). The steeper the valley floor, the deeper is the transport into the valley and less parcels are advected back over the foreland on average (see REF and I1_5 simulation). The transport into the valley dominates, if the valley width is increased (e.g. W30, W40) and is further intensified by narrowing the valley width and tilting the valley floor (e.g. W40N and W40NI). In these cases most of the parcels are located far away from the slopes, which prevents vertical transport by upslope winds.

If the trajectories are started $10 \mathrm{~km}$ over the foreland (Fig. 14) all parcels stay below the reference entrainment layer height (PLAIN-PBL3). Parcels of the REF run and of simulations with inclined valley floor (I0_375 to I1_5) show average heights at mixed layer height (PLAIN-PBL2) at the end of the simulation. The percentage of parcels above PLAIN-PBL2 (50 to $60 \%$ ) and PLAIN-PBL3 (25 to $36 \%$ ) is nearly 6 and 72 times larger as over the convective boundary layer of the PLAIN simulation (10 and $0.5 \%$, respectively, Fig. 14b, c). For wide valleys (e.g. W40, W40N, W40NI) the percentage of parcels above PLAIN-PBL2 is considerably lower than in the PLAIN simulation (Fig. 14b) due to directed upvalley flows, which reduce vertical mixing. The higher density of parcels near the surface in these simulations compared to the PLAIN case is also visible in Fig. 11. The increased along-valley transport in simulations with both inclined valley floors and narrowing valley widths is shown with average along-valley positions of up to $70 \mathrm{~km}$ (W30NI) in Fig. 14d.

\section{Conclusions}

Idealized simulations of thermally driven flows over a valley-plain topography under daytime conditions are performed. The valley topography is varied systematically in the along-valley direction by tilting the valley floor and narrowing the valley width to investigate the impact of along-valley terrain heterogeneities on the boundary layer structure and transport processes.

Simulations with inclined valley floors reveal a significant increase of the temperature contrast between the valley and the foreland and intensify the upvalley flow due to the valley volume effect and due to additional upslope buoyancy forces along the inclined valley floor. The computation of average 

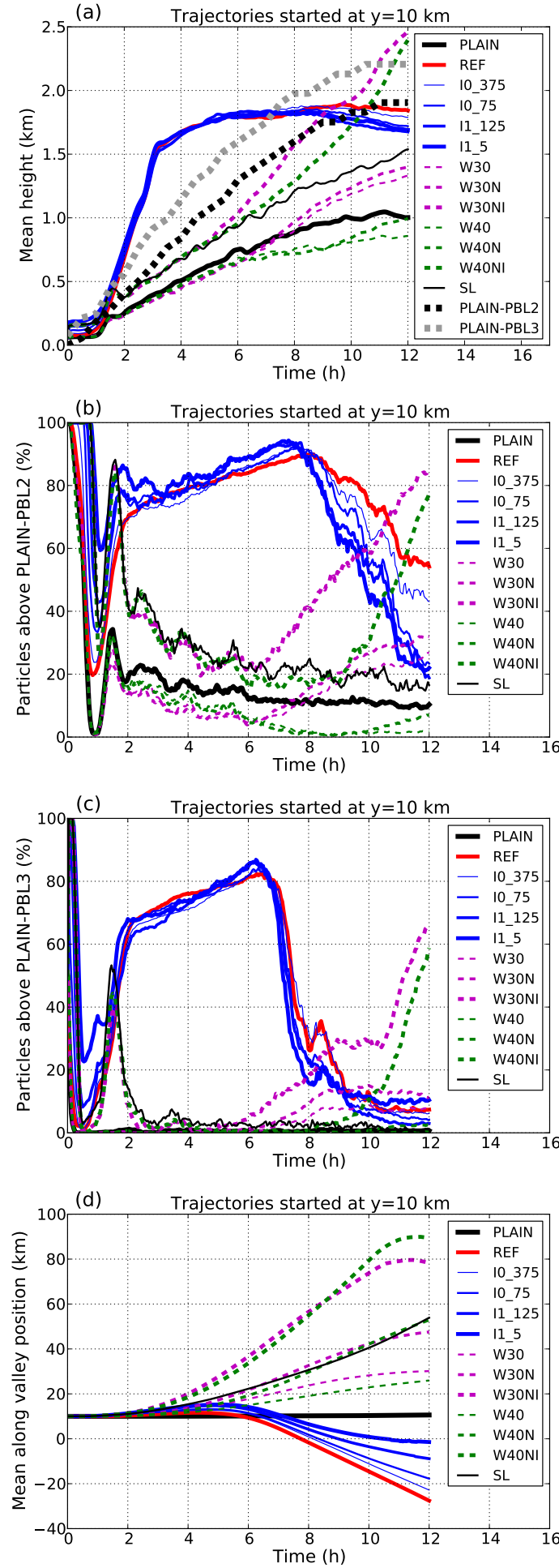

Figure 13. Time series of (a) mean trajectory height, (b) fraction of parcels, which are located above PLAIN-PBL2 and (c) above PLAIN-PBL3 and (d) mean along-valley position of parcels started at $y=10 \mathrm{~km}$. The thick black and grey dashed lines in (a) mark the PLAIN-PBL2 and PLAIN-PBL3 height, respectively.
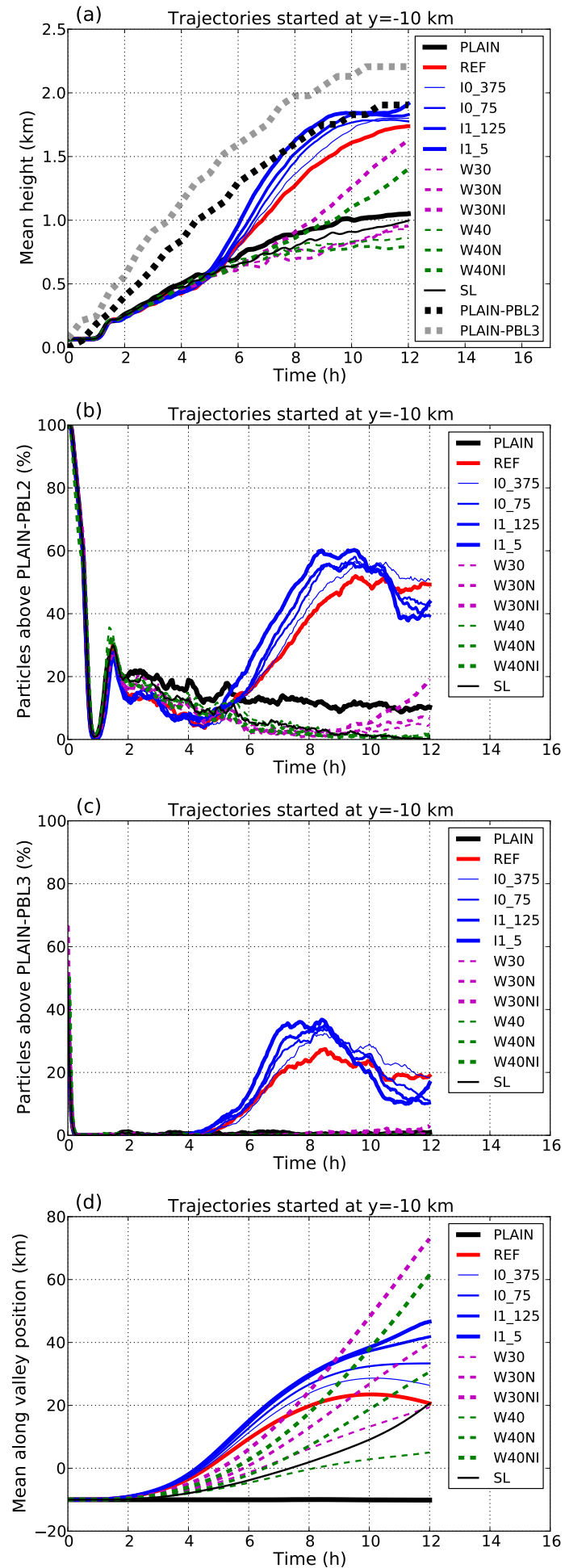

Figure 14. Time series of (a) mean trajectory height, (b) fraction of parcels, which are located above PLAIN-PBL2 and (c) above PLAIN-PBL3 and (d) mean along-valley position of parcels started at $y=-10 \mathrm{~km}$. The thick black and grey dashed lines in (a) mark the PLAIN-PBL2 and PLAIN-PBL3 height, respectively. 
valley-volume upvalley wind speeds shows that a reduction of the valley volume by $50 \%$ increases wind speeds by a factor of about 1.9, while tilting the valley floor by angles of $0.86^{\circ}$ amplifies wind speeds by a factor of about 1.6. Narrowing the valley cross sections increases upvalley winds by a factor of about 2.6. Upvalley winds penetrate much deeper into the valley if the valley floor is inclined or the valley becomes narrower. All valley-plain simulations develop a valley inversion layer, which separates two vertically stacked circulation cells. As in Wagner et al. (2014a) these cells are weaker for wider valleys. A mountain-to-plain return flow establishes above this valley inversion layer and extends up to $80 \mathrm{~km}$ over the foreland.

Mass fluxes into and out of the valley at mountain crest height are computed to quantify horizontal and vertical transport processes in the different valleys. The strongest mass flux amplification factor between 1.8 and 2.8 (compared to straight valleys) is achieved by narrowing valley cross sections. Tilting the valley floor by angles of $0.86^{\circ}$ increases mass fluxes by a factor of about 1.2.

Trajectory analyses are performed to study differences in transport processes from the surface out of the valley and into the free atmosphere. In the REF run a minor part of the parcels is transported up to $60 \mathrm{~km}$ into the valley along the valley floor, whereas the major part is advected towards the mountain ridges by upslope winds and lifted to high altitudes by convective cells over the mountain crests. Most parcels are then captured by the return flow and transported into the free atmosphere above the foreland. The vertical transport of parcels is not significantly increased compared to the REF run by tilting the valley floors in straight valleys (e.g. I0_375, I1_5) and by narrowing the valley cross section (e.g. W30N, W40N). This is not in contrast to mass flux analyses, as different reference heights are used and trajectory analyses are based on a thin layer of parcels started near the surface, whereas mass flux budgets are computed for the whole valley volume. Vertical transport of parcels is, however, increased in narrowing valleys with inclined valley floors (W30NI, W40NI) at the end of the simulations. In these cases upvalley winds are strong enough to advect a large number of parcels to the plateau-like valley end, where they are lifted to higher altitudes by convective cells.

Horizontal transport of parcels into the valley is considerably increased by inclined valley floors and narrowing valley widths due to the stronger along-valley flow. This result is in agreement with stronger horizontal mass fluxes into the valley in these cases. The deeper transport of parcels into the valley reduces the number of parcels, which are transported back over the foreland by the return flow. Horizontal transport dominates especially in wider valleys with narrowing valley widths and inclined valley floors (e.g. W40N, $\mathrm{W} 40 \mathrm{NI}$ ), as most of the parcels are located far away from the slopes and cannot be captured by cross-valley upslope winds.

The results of this study together with the conclusions of Wagner et al. (2014a) show that valley depth, width, valley floor inclination and narrowing valley cross sections have an important influence on the daytime boundary layer structure of a valley and related horizontal and vertical transport processes of properties from the surface to the free atmosphere. Future boundary layer parametrization schemes for coarse scale atmospheric weather and climate models that do not (or not entirely) resolve these flows should consider these valley geometry parameters beside other effects such as different land-use types, surface forcings and background stabilities. The development of such a parametrization will be quite difficult, but could be based on a similar technique as applied in gravity wave drag parametrizations of coarse-resolution models (see Kim et al., 2003). This means that the subgridscale topography of a model grid box could be reduced to an idealized valley-plain topography with certain geometry properties by means of Fourier analysis. This would then allow us to compute subgrid-scale vertical fluxes in dependence of factors like valley geometry and surface forcing, which could then improve boundary layer profiles over complex terrain. Such parametrizations are needed especially for global NWP and climate models, whose horizontal resolution will likely be too coarse to properly simulate processes on a scale below about $10 \mathrm{~km}$ in the next decades.

Acknowledgements. This work was supported by the Austrian Science Fund (FWF) under grant P23918-N21 and by the Austrian Ministry of Science BMWF as part of the UniInfrastrukturprogramm of the Research Platform Scientific Computing at the University of Innsbruck.

Edited by: H. Wernli

\section{References}

Catalano, F. and Cenedese, A.: High-resolution numerical modeling of thermally driven slope winds in a valley with strong capping, J. Appl. Meteorol., 49, 1859-1880, 2010.

Catalano, F. and Moeng, C.-H.: Large-eddy simulation of the daytime boundary layer in an idealized valley using the Weather Research and Forecasting numerical model, Bound.-Lay. Meteorol., 137, 49-75, doi:10.1007/s10546-010-9518-8, 2010.

Colette, A., Chow, F. K., and Street, R. L.: A numerical study of inversion-layer breakup and the effects of topographic shading in idealized valleys, J. Appl. Meteorol., 42, 1255-1272, doi:10.1175/1520-0450(2003)042<1255:ANSOIB>2.0.CO;2, 2003.

Deardorff, J. W.: Stratocumulus-capped mixed layers derived from a 3-dimensional model, Bound.-Lay. Meteorol., 18, 495-527, 1980.

Egger, J.: Atmospheric processes over complex terrain, Vol. 23, chap. Thermally forced flows: Theory, 43-58, Amer. Meteor. Soc., 1990.

Henne, S., Furger, M., Nyeki, S., Steinbacher, M., Neininger, B., de Wekker, S. F. J., Dommen, J., Spichtinger, N., Stohl, A., and Prevot, A. S. H.: Quantification of topographic venting of bound- 
ary layer air to the free troposphere, Atmos. Chem. Phys., 4, 497509, doi:10.5194/acp-4-497-2004, 2004.

Kim, Y.-J., Eckermann, S. D., and Chun, H.-Y.: An overview of the past, present and future of gravity-wave drag parameterization for numerical climate and weather prediction models, Atmos.Ocean, 41, 65-98, doi:10.3137/ao.410105, 2003.

Li, J.-G. and Atkinson, B. W.: Transition regimes in valley air flows, Bound.-Lay. Meteorol., 91, 385-411, 1999.

Monin, A. S. and Obukhov, A. M.: Basic laws of turbulent mixing in the ground layer of the atmosphere, Akad. Nauk SSSR Geofiz. Inst. Tr., 151, 163-187, 1954.

Prandtl, L.: Mountain and valley winds in stratified air, Essentials of Fluid Dynamics, 422-425, 1952.

Rampanelli, G., Zardi, D., and Rotunno, R.: Mechanisms of upvalley winds, J. Atmos. Sci., 61, 3097-3111, doi:10.1175/JAS3354.1, 2004.

Riday, C.: The influence of valley geometry on the diurnal valley winds, Master's thesis, Institute of Atmospheric and Climate Sciences ETH Zürich, 2010.

Rotach, M. W. and Zardi, D.: On the boundary-layer structure over highly complex terrain: Key findings from MAP, Q. J. Roy. Meteor. Soc., 133, 937-948, 2007.

Rotach, M. W., Wohlfahrt, G., Hansel, A., Reif, M., Wagner, J. S., and Gohm, A.: The world is not flat - implications for the global carbon balance, B. Am. Meteorol. Soc., 95, 1021-1028, doi:10.1175/BAMS-D-13-00109.1, 2014.

Schmidli, J.: Daytime heat transfer processes over mountainous terrain, J. Atmos. Sci., 70, 4041-4066, doi:10.1175/JAS-D-13083.1, 2013.

Schmidli, J. and Rotunno, R.: Mechanisms of along-valley winds and heat exchange over mountainous terrain, J. Atmos. Sci., 67, 3033-3047, 2010.

Schmidli, J., Billings, B., Chow, F. K., de Wekker, S. F. J., Doyle, J., Grubisić, V., Holt, T., Jiang, Q., Lundquist, K. A., Sheridan, P., Vosper, S., Whiteman, C. D., Wyszogrodzki, A. A., and Zängl, G.: Intercomparison of mesoscale model simulations of the daytime valley wind system, Mon. Weather Rev., 139, 1389-1409, 2011.

Schumann, U.: Large-eddy simulation of the up-slope boundary layer, Q. J. Roy. Meteor. Soc., 116, 637-670, doi:10.1002/qj.49711649307, 1990.
Serafin, S. and Zardi, D.: Daytime heat transfer processes related to slope flows and turbulent convection in an idealized mountain valley, J. Atmos. Sci., 67, 3739-3756, 2010.

Skamarock, W. C., Klemp, J. B., Dudhia, J., Gill, D. O., Barker, D. M., Duda, M. G., Huang, X.-Y., Wang, W., and Powers, J. G.: A description of the Advanced Research WRF Version 3, NCAR technical note, Mesoscale and Microscale Meteorology Division, National Center for Atmospheric Research, Boulder, Colorado, USA, 2008.

Stoelinga, M. T.: A users guide to RIP Version 4.4: A program for visualizing mesoscale model output, available at: http://www2. mmm.ucar.edu/wrf/users/docs/ripug.htm (last access: 12 June 2015), 2009.

Vergeiner, I. and Dreiseitl, E.: Valley winds and slope winds - Observations and elementary thoughts, Meteorol. Atmos. Phys., 36, 264-286, 1987.

Vergeiner, I., Dreiseitl, E., and Whiteman, C. D.: Dynamics of katabatic winds in Colorado' Brush Creek valley, J. Atmos. Sci., 44, 148-158, 1987.

Wagner, A.: Theorie und Beobachtung der periodischen Gebirgswinde, Gerlands Beitr. Geophys., 52, 408-449, 1938.

Wagner, J. S., Gohm, A., and Rotach, M. W.: The impact of valley geometry on daytime thermally driven flows and vertical transport processes, Q. J. Roy. Meteor. Soc., doi:10.1002/qj.2481, 2014a.

Wagner, J. S., Gohm, A., and Rotach, M. W.: The impact of horizontal model grid resolution on the boundary layer structure over and idealized valley, Mon. Weather Rev., 142, 3446-3465, doi:10.1175/MWR-D-14-00002.1, 2014b.

Weigel, A. P., Chow, F. K., and Rotach, M. W.: The effect of mountainous topography on moisture exchange between the "surface" and the free atmosphere, Bound.-Lay. Meteorol., 125, 227-244, doi:10.1007/s10546-006-9120-2, 2007.

Weissmann, M., Busen, R., Dörnbrack, A., Rahm, S., and Reitebuch, O.: Targeted observations with an airborne wind lidar, J. Atmos. Ocean. Tech., 22, 1706-1719, 2005.

Whiteman, C. D.: Mountain meteorology: Fundamentals and applications, Oxford University Press, 2000.

Zhang, D.-L. and Anthes, R. A.: A high-resolution model of the planetary boundary layer - sensitivity tests and comparisons with SESAME-79 data, J. Appl. Meteorol., 21, 1594-1609, 1982. 